\title{
Verfassungsrechtliche Grenzen des Infektionsschutzes
}

\author{
Horst Dreier $\left.{ }^{\square}\right)$ \\ Ehem. Professor für Rechtsphilosophie, Staats- und Verwaltungsrecht, \\ Universität Würzburg, Würzburg, Deutschland \\ dreier@mail.uni-wuerzburg.de
}

Schlïsselwörter: Rechtsstaat · Föderalismus · Grundrechte

Der vorliegende Text ist die überarbeitete, erweiterte und mit Anmerkungen versehene Fassung des Vortrages, den der Autor am 30. Oktober 2020 im Rahmen der Tagung „Infektionen und Gesellschaft“ gehalten hat. Knapp drei Wochen später hat der Bundestag mit Zustimmung des Bundesrates teils substanzielle Änderungen des einschlägigen Infektionsschutzgesetzes vorgenommen ${ }^{1}$. Diese Novellierungen sind in den Text eingearbeitet worden: Jeweils am Ende eines Kapitels wird die Relevanz der Änderungen für die Ausführungen beschrieben, die sich auf die bis Mitte November geltende Rechtslage beziehen. Diese ,alte“ Rechtslage ist freilich nicht überholt oder ab sofort gegenstandslos. Denn da sich alle zwischen März und Mitte November 2020 getroffenen Corona-Schutzmaßnahmen auf die ursprünglichen Regelungen stützen und die Vielzahl der gerichtlichen Entscheidungen dazu praktisch ausnahmslos im vorläufigen Rechtsschutz ergingen, werden in Zukunft noch zahlreiche Hauptsacheverfahren bis hin zu bundesverfassungsgerichtlichen Entscheidungen folgen. Deshalb bleibt die ,alte“ Rechtslage von ungebrochener Relevanz und praktischer Bedeutung.

\section{Das Grundgesetz als Vorgabe}

Die Grenzen der staatlichen Maßnahmen zur Bekämpfung der aktuellen CoronaPandemie werden durch die Vorgaben des Grundgesetzes gebildet. Diese Aussage mag man als trivial empfinden: Die verfassungsrechtlichen Grenzen sind eben die Grenzen der Verfassung. Doch dieser Eindruck täuscht. Denn mit dieser Aussage steht zugleich fest, dass es in Deutschland keinen Rückgriff auf ein ungeschriebenes Notstandsrecht gegeben hat, das über der geschriebenen Verfassung steht. Ein solcher Ausnahmezustand suspendiert nach klassischem Verständnis das geltende Recht und setzt es für gewisse Zeit außer Kraft. In der Bundesrepublik hingegen sind bislang alle einschlägigen Maßnahmen zur Bekämpfung der Pandemie (Parlamentsgesetze,

1 „Drittes Gesetz zum Schutz der Bevölkerung bei einer epidemischen Lage von nationaler Tragweite" vom 18. November 2020 (BGB1. I S. 2397). 
Rechtsverordnungen der Exekutive, Allgemeinverfügungen oder Einzelverwaltungsakte der Behörden) auf den verfassungsrechtlich vorgesehenen Bahnen und im üblichen Verfahren erlassen worden. Das Grundgesetz beansprucht somit auch im aktuellen Krisenfall ungeschmälert Geltungskraft. Die Pandemie ist im Rahmen der allgemeinen Verfassungsordnung zu bewältigen. Daher befinden wir uns in Deutschland zweifellos in einem außergewöhnlichen Zustand, aber - entgegen einer in der Öffentlichkeit verbreiteten Terminologie - bei verfassungsrechtlicher Betrachtung nicht in einem Ausnahmezustand ${ }^{2}$.

Das hat konkrete Folgen für die hier interessierende Frage, ob möglicherweise im Zuge der Bekämpfung der Pandemie Vorgaben des Grundgesetzes verletzt worden sind. Denn insofern gilt das normale „Prüfprogramm“, gelten also die gleichen verfassungsrechtlichen Maßstäbe wie in normale(re)n Zeiten. In der öffentlichen Debatte steht seit Anbeginn der Pandemiebekämpfung die Frage im Zentrum, ob die nach Ausmaß, Intensität und Dauer beispiellosen Einschränkungen der Grundrechte einer näheren verfassungsrechtlichen Prüfung standhalten oder ob die entsprechenden Maßnahmen, salopp gesprochen, den Bogen überspannt haben. Dieser Aspekt soll im Folgenden nicht fehlen (dazu 5). Ebenso herausragende Bedeutung kommt aber neben den Grundrechten anderen Verfassungsprinzipien zu, wie sie in Art. 20 Abs. 1 bis 3 GG verankert sind: Rechtsstaat, Föderalismus und Demokratie (dazu 2 bis 4). Gerade weil die hier aufscheinenden Probleme in der Öffentlichkeit weit weniger intensiv zur Kenntnis genommen, sogar oft überhaupt nicht registriert worden sind, seien sie an den Anfang des Beitrages gestellt.

\section{Rechtsstaat}

\subsection{Das Problem der infektionsschutzrechtlichen Generalklausel}

Der Vorbehalt des Gesetzes. Der Rechtsstaat bildet einen zentralen Pfeiler in der Architektur des Grundgesetzes ${ }^{3}$. Eines seiner wichtigsten Elemente ist der Vorbehalt des Gesetzes, ein Grundsatz, der schon im konstitutionellen Staatsrecht des 19. Jahrhunderts anerkannt war. Der Vorbehalt des Gesetzes besagt, dass alle Eingriffe der Exekutive in die Freiheitssphäre der Bürger einer gesetzlichen Grundlage bedürfen. Der Merksatz lautet: keine Maßnahme ohne Gesetz.

Die infektionsschutzrechtliche Generalklausel. Bekanntlich werden nun die staatlichen Maßnahmen zur Bekämpfung des Corona-Virus auf das Infektionsschutzgesetz (IfSG) gestützt. Dieses kennt zwar wenige näher spezifizierte Standardbefugnisse ( $\$$ 29: Beobachtung; § 30: Quarantäne; § 31: Berufliches Tätigkeitsverbot). Doch der Löwenanteil der staatlichen Maßnahmen, die in der allerersten Phase in

2 Wie hier Jens Kersten/Stephan Rixen: Der Verfassungsstaat in der Corona-Krise, S. 27 ff., $33 \mathrm{ff}$. München (2020).

3 Kompakter Überblick zur Genese und zu den Teilelementen des Rechtsstaatsprinzips: Horst Dreier: Idee und Gestalt des freiheitlichen Verfassungsstaates, S. 23-38 (25 ff., 31 ff.). Tübingen (2014). 
der Form von Allgemeinverfügungen, schon bald aber allein als Rechtsverordnungen der Länder gemäß § 32 IfSG ergangen sind, stützt sich auf die Bestimmung des § 28 Abs. 1 Satz 1 IfSG. Danach, ,trifft die zuständige Behörde die notwendigen Schutzmaßnahmen, [...] soweit und solange es zur Verhinderung der Verbreitung übertragbarer Krankheiten erforderlich ist" ${ }^{" 4}$. Bei dieser Norm, die nur durch einige wenige und keineswegs abschließende Regelbeispiele (Betretungs-, Veranstaltungsund Ansammlungsverbote) etwas näher profiliert wird, handelt es sich um eine infektionsschutzrechtliche Generalklausel, weil die Maßnahmen nicht genauer spezifiziert sind, sondern nur allgemein von den ,notwendigen Schutzmaßnahmen“ die Rede ist ${ }^{5}$. Als Tatbestandsvoraussetzung für die Ergreifung dieser Maßnahmen firmiert allein: „Werden Kranke, Krankheitsverdächtige, Ansteckungsverdächtige oder Ausscheider festgestellt ..." ( $\$ 28$ Abs. 1 IfSG). Dennoch liegt mit dieser schmalen, ja spärlichen Norm ein Gesetz vor, sodass bei rein formaljuristischer Betrachtung das rechtsstaatliche Erfordernis des Vorbehalts des Gesetzes als erfüllt anzusehen ist.

Die Wesentlichkeitslehre. Doch diese Betrachtung reicht nicht aus, weil die sogenannte Wesentlichkeitslehre ins Spiel kommt ${ }^{6}$. Denn schon seit langem ist es herrschende Rechtsauffassung in Judikatur wie Literatur, dass der förmliche, also der parlamentarische Gesetzgeber die wesentlichen Entscheidungen selbst treffen muss, sie also nicht im Wege einer Generalklausel einfach der Exekutive überlassen darf. Und als ,wesentliche“ Entscheidungen gelten nach der unbestrittenen Rechtsprechung des Bundesverfassungsgerichts insbesondere solche, die die Grundrechtsausübung betreffen. Es kann mithin kein vernünftiger Zweifel daran bestehen, dass die Pandemiebekämpfung mit ihren außerordentlich weitreichenden

${ }^{4}$ Das „Gesetz zur Verhütung und Bekämpfung von Infektionskrankheiten beim Menschen (Infektionsschutzgesetz - IfSG)“ stammt aus dem Jahre 2000. Es wurde nach Ausbruch der Corona-Pandemie zunächst geändert durch das „Gesetz zum Schutz der Bevölkerung bei einer epidemischen Lage von nationaler Tragweite“ v. 27. Mai 2020 (BGB1. I S. 587), das am 28. März 2020 in Kraft getreten ist. Weitere hier interessierende Änderungen erfolgten durch ein „Zweites Gesetz zum Schutz der Bevölkerung bei einer epidemischen Lage von nationaler Tragweite“ vom 19. Mai 2020 (BGBl. I S. 1018). An der grundsätzlichen Struktur der Bekämpfungsmaßnahmen gemäß $\S 28$ ff. (Generalklausel mit wenigen Regelbeispielen und die Standardbefugnisse in $\S \S 29,30,31$ IfSG) hat sich durch diese Gesetze nichts geändert. Doch wurde durch einige eher unscheinbar anmutende redaktionelle Änderungen des $§ 28$ im ersten Gesetz vom März 2020 das Bestreben erkennbar, von der ursprünglich dominierenden Leitvorstellung lokal und zeitlich begrenzter Ausbrüche abzurücken und auf sehr viel größere und länger andauernde Prozesse umzusteuern; vgl. dazu etwa Stephan Rixen, Gesundheitsschutz in der Coronavirus-Krise. Die (Neu-)Regelungen des Infektionsschutzgesetzes, In: NJW S. 1097-1103 (1099) (2020).

5 Näher hierzu (auch zur verfassungsrechtlichen Problematik) aus der Kommentarliteratur etwa Sebastian Kluckert: Verfassungs- und verwaltungsrechtliche Grundlagen des Infektionsschutzrechts, In: ders. (Hrsg.) Das neue Infektionsschutzrecht, Baden-Baden (2020), § 2 Rn. $80 \mathrm{ff}$.

$6 \mathrm{Zu}$ ihr statt vieler: Dieter Hömig: Grundlagen und Ausgestaltung der Wesentlichkeitslehre, In: Festgabe 50 Jahre Bundesverwaltungsgericht, herausgegeben von Eberhard SchmidtAßmann u. a., S. 273-288, Köln u. a. (2003). 
und praktisch die Gesamtbevölkerung betreffenden Grundrechtsbeschränkungen einen Musterfall für die Anwendung der Wesentlichkeitslehre darstellt ${ }^{7}$. Wichtige Konsequenz: „Die Qualifikation einer Regelung als ,wesentlich“ hat typischerweise ein Verbot der Normdelegation und ein Gebot größerer Regelungsdichte durch den parlamentarischen Gesetzgeber zur Folge. “8

Konkret bedeutet das: Auch wenn sich der alleinige Rückgriff auf die infektionsschutzrechtliche Generalklausel in der Anfangsphase der Pandemie noch durch die absolut neue Situation rechtfertigen ließ, so ist sie doch auf Dauer als Rechtsgrundlage untauglich, weil es spezifischer gesetzlicher Vorgaben bedarf. Auf diesen Punkt wurde schon seit längerem und mit wachsendem Nachdruck in der verfassungsrechtlichen Literatur hingewiesen ${ }^{9}$. Zudem haben die Gerichte in jüngerer Zeit vermehrt eine präzisere gesetzliche Ermächtigung für die grundrechtseinschränkenden Rechtsverordnungen der Länder gefordert ${ }^{10}$. Besonders deutlich ist nach mehr als acht Monaten unlängst nochmals der Bayerische Verwaltungsgerichtshof geworden, der seinen Leitsatz zur Entscheidung wie folgt fasst: ,Mit der zeitlichen Intensität der bislang nur im Rahmen von Rechtsverordnungen der Exekutive geregelten Maßnahmen zur Bekämpfung der SARS-CoV-2-Pandemie verschärfen sich die Anforderungen des Parlamentsvorbehalts aus Art. 80 Abs. 1 Satz 1 und 2 GG. " ${ }^{11}$ Dieser richterliche Hinweis auf Art. 80 GG erklärt sich daraus, dass mittlerweile so gut wie alle Maßnahmen der (allein zuständigen) Bundesländer in Gestalt von Rechtsverordnungen erlassen werden. Dazu ermächtigt § 32 IfSG, dessen Satz 1 lautet: „Die Landesregierungen werden ermächtigt, unter den Voraussetzungen, die für Maßnahmen nach den $\S \S 28$ bis 31 maßgebend sind, auch durch Rechtsverordnungen entsprechende Gebote und Verbote zur Bekämpfung übertragbarer Krankheiten zu erlassen. “ Hier führt die Vagheit der Generalklausel wegen der Scharnierfunktion des $§ 32$ IfSG also dazu, dass es an der notwendigen Bestimmtheit der Rechtsverordnung fehlt, an die Art. 80 Abs. 1 Satz 2 GG strenge Anforderungen stellt ${ }^{12}$. Das demonstriert die enge Verwandtschaft von allgemeiner Wesentlichkeitslehre und speziellem Bestimmtheitsgebot für Rechtsverordnungen.

7 Kluckert (Fn. 5), § 2 Rn. 105.

8 Zitat: Entscheidungen des Bundesverfassungsgerichts (im folgenden abgekürzt: BVerfGE), Bd. 150, S. 1 (97 f., Rn. 195).

9 Z.B. Johannes Lichdi: Die Geltung des Parlamentsvorbehalts in der Corona-Pandemie, In: SächsVB1. S. 273-279 (2020); Uwe Volkmann: Heraus aus dem Verordnungsregime, In: NJW, S. 3153-3160 (2020), beide mit weiteren Nachweisen.

10 Es gab schon früh gerichtliche Hinweise auf diesen kritischen Punkt: OVG Münster v. 6. April 2020, 13 B 398/20.NE, Rn. 63 ff. (bei openjur); VGH Mannheim v. 9. April 2020, 1 S. 925/20, Ls. 3. - Ähnlich BayVGH v. 27. April 2020, 20 NE 20.793, Rn. 45.

11 BayVGH v. 29. Oktober 2020, 20 NE 20.2360; das ist in Rn. 28 ff. näher und mit Nachdruck ausgeführt. - Ähnlich deutlich: Verfassungsgerichtshof des Saarlandes v. 28. August 2020, Lv 15/20, abgedruckt in: NVwZ 2020, S. 1513 (1518). Allerdings gibt es auch Entscheidungen anderer Gerichte, die (derzeit) keine Zweifel an der Anwendbarkeit der Generalklausel hegen.

12 Vgl. dazu noch unter Punkt 2.2. 
Doch ist, was nicht immer hinlänglich klar gesehen wird, ihr Anwendungsbereich nicht deckungsgleich. Würden die Länder nicht durchweg von der Möglichkeit des $\S 32$ IfSG Gebrauch machen, sondern deren Regierungen oder Behörden ihre Maßnahmen allein und direkt auf $\S 28$ IfSG stützen, indem sie (wie zu Beginn der Pandemie geschehen) Allgemeinverfügungen erließen, wäre die Problemzone des Art. 80 GG gar nicht berührt. Es bestünde aber immer noch das aufgezeigte Zentralproblem, dass das normative Entscheidungsprogramm des § 28 IfSG nicht den Vorgaben der Wesentlichkeitslehre entspricht.

Man wird nicht ganz fehlgehen in der Annahme, dass es - neben kritischen Stimmen aus der Rechtswissenschaft und Forderungen der Oppositionsfraktionen vor allem die erwähnten deutlichen Hinweise aus der gerichtlichen Spruchpraxis waren, die die Regierungsfraktionen dazu bewogen haben, hier signifikant nachzubessern $^{13}$.

Änderung der Rechtslage durch die Novelle vom November 2020. Denn durch das Gesetz vom November $2020^{14}$ ist mit dem neuen § 28a IfSG zum einen eine Norm eingefügt worden, die spezifisch auf die aktuelle Corona-Pandemie zugeschnitten ist. Sie trägt die Überschrift „Besondere Schutzmaßnahmen zur Verhinderung der Verbreitung der Coronavirus-Krankheit-2019 (COVID-19)“ und listet in 17 Punkten so gut wie alle derjenigen Maßnahmen auf, die sich bislang auf die infektionsschutzrechtliche Generalklausel (in Verbindung mit den Rechtsverordnungen der Länder) stützen müssen: Abstandsgebot, Maskenpflicht, Ausgangs- und Kontaktbeschränkungen, Betretungsverbote, Betriebs- und Geschäftsschließungen, Untersagung von Veranstaltungen und anderes mehr. Das sind zwar weiterhin (nur) nicht abschließend aufgezählte Regelbeispiele, die ihrerseits nicht in eine Hierarchie gebracht wurden ${ }^{15}$. Allerdings werden nunmehr ausdrücklich die Ziele der ergriffenen Maßnahmen benannt (der Schutz von Leben und Gesundheit sowie die Funktionsfähigkeit des Gesundheitssystems). Zudem sind anhand von Inzidenzwerten in grober Typisierung Schweregrade mit entsprechend höheren oder niedrigeren Eingriffsschwellen vorgegeben.

Begrüßenswert erscheint zum anderen die Klarstellung, dass die Maßnahmen des $\S 28$ a nur bei Feststellung einer epidemischen Lage von nationaler Tragweite ergriffen werden können - und dass diese Feststellung, die bislang an materielle Kriterien nicht gebunden war, nun in $\S 5$ Abs. 1 Satz 4 IfSG an bestimmte, wenn auch weitgefasste Voraussetzungen (Ausrufung einer Pandemie durch die WHO oder dynamische Ausbreitung) geknüpft ist. Insgesamt sind durch $\S \S 5$, 28a IfSG die tatbestandlichen Voraussetzungen, die sich zuvor in den dürren Worten des $§ 28$ Abs. 1 IfSG (,Werden

13 BT-Drs. 19/23.944.

14 Vgl. oben Fn. 1.

15 Wenn man davon absieht, dass in $\S 28 \mathrm{a}$ Abs. 2 IfSG für einige besonders sensible und eingriffsintensive Maßnahmen (Versammlungen und religiöse Veranstaltungen, Ausgangsbeschränkungen und Zugang zu Krankenhäusern und Heimen) noch einmal schärfe Voraussetzungen aufgestellt werden. Sie sollen nur zulässig sein, ,soweit auch bei Berücksichtigung aller bisher getroffenen Maßnahmen“ eine wirksame Eindämmung des Virus „erheblich gefährdet wäre“. 
Kranke, Krankheitsverdächtige [etc.] festgestellt, [...]“) erschöpften, nunmehr deutlich geschärft. Dass Rechtsverordnungen gemäß § 32 IfSG nunmehr mit einer allgemeinen Begründung zu versehen sind ( $\$ 28 \mathrm{a}$ Abs. 5 IfSG), dürfte gleichermaßen zur höheren Bestimmtheit der jeweils erlassenen Maßnahmen beitragen. Obgleich damit die infektionsschutzrechtlichen Normen noch nicht die Präzision gefahrenabwehrrechtlicher Befugnisse erreicht haben, so ist doch insgesamt ein erheblicher Gewinn an rechtsstaatlicher Bestimmtheit und demokratischer Legitimation zu verzeichnen. Nicht übersehen werden darf bei alledem aber, dass diese Neuregelungen erst ab Inkrafttreten (19. November 2020) gelten. Sowohl der erste Lockdown im März 2020 als auch der zweite Anfang November des Jahres sowie alle in der Zwischenzeit ergriffenen Schutzmaßnahmen beruhten weitestgehend auf der - wie dargelegt problematischen - Grundlage der infektionsschutzrechtlichen Generalklausel. Die Rechtmäßigkeit jener zahlreich angefochtenen Maßnahmen wird in nächster Zeit Gegenstand vieler (verwaltungs-)gerichtlicher Entscheidungen in Hauptsacheverfahren sein.

\subsection{Das Problem gesetzesverändernder Rechtsverordnungen}

Normenhierarchie. Zur rechtsstaatlichen Ordnung gehört auch eine ,hierarchische Bindung" des Rechts ${ }^{16}$. Danach ist die gesetzgebende Gewalt an die Vorgaben der Verfassung, die Exekutive als vollziehende Gewalt aber ihrerseits an die Gesetze gebunden. Art. 20 Abs. 3 GG drückt das so aus: „Die Gesetzgebung ist an die verfassungsmäßige Ordnung, die vollziehende Gewalt und die Rechtsprechung sind an Gesetz und Recht gebunden. "17 Für den besonderen Fall exekutiver Rechtsetzung findet die allgemeine Gesetzesbindung der Verwaltung eine Konkretisierung in Art. 80 GG. Man kann dessen Kernaussage schlicht so formulieren: Rechtsverordnungen müssen sich im Rahmen der gesetzlichen Vorgaben halten. Diese stehen nicht zur Disposition der Verwaltung, sondern bilden ihre unverrückbare Vorgabe.

Diese verfassungsrechtlich fundierte Normenhierarchie wird nun durch einige Bestimmungen des Infektionsschutzgesetzes auf den Kopf gestellt. So ermächtigen $\S$ 5 Abs. 2 Nr. 3, 4, 7 und 8 das Gesundheitsministerium dazu, von einer Vielzahl von Gesetzen abzuweichen, insbesondere bestimmte Ausnahmen von gesetzlichen Vorschriften zuzulassen. Der Inhalt der Gesetze wird hier in gewissem Umfang durch die Exekutive bestimmt.

Zulässige Anwendungsbeschränkungen? $\mathrm{Zu}$ rechtfertigen sind diese Ermächtigungen nicht durch den Hinweis darauf, dass sie nicht völlig unüblich seien, weil in anderen Gesetzen ebenfalls gewisse Anwendungsbeschränkungen durch die Exekutive vorgesehen sind und das Bundesverfassungsgericht diese gebilligt habe ${ }^{18}$.

16 Terminus: Helmuth Schulze-Fielitz In: Horst Dreier (Hrsg.), Grundgesetz-Kommentar, Bd. II, 3. Aufl., Art. 20 (Rechtsstaat), Rn. 81 ff. Tübingen (2015).

17 Die schwierige und umstrittene Frage, was insofern unter „Recht“ zu verstehen ist (dazu Schulze-Fielitz [Fn. 16], Art. 20 [Rechtsstaat], Rn. 92 ff.), kann hier auf sich beruhen.

18 Tendenziell in diese Richtung etwa Annette Guckelberger: Flexiblere Abänderung von Rechtsvorschriften aufgrund der Corona-Pandemie?, in: DVBl. S. 1441-1448 (1443 ff.) (2020). 
Denn es gibt gravierende Unterschiede. Zum einen wurde das Gesetz in jenen Fällen (etwa im Betäubungsmittel- oder im Ladenschlussrecht) unter dem Vorbehalt genau festgelegter Änderungsmodalitäten erlassen. Die Änderung der Rechtslage ist also bereits im Gesetz selbst vorgesehen; dieses hat sich eine solche Beschränkungsmöglichkeit sozusagen im gleichen Atemzug beigelegt. Zum anderen sind die Anwendungsbeschränkungen auf eher marginale, oft technische Gesichtspunkte bezogen und tatbestandlich eng umschrieben.

Als Beispiel für beide Aspekte mag § 1 Abs. 2 BtMG dienen. Danach darf die Bundesregierung die in den Anlagen zum Gesetz aufgeführten Listen der einschlägigen Stoffe und Zubereitungen ändern oder ergänzen (und damit den tatsächlichen Veränderungen auf dem Betäubungsmittelmarkt Rechnung tragen), aber zum einen erst nach Anhörung von Sachverständigen, zum zweiten allein durch eine mit Zustimmung des Bundesrates erlassene Rechtsverordnung und drittens nur, wenn die in $\S 1$ Abs. 2 Satz 1 Nr. 1-3 BtMG genannten Voraussetzungen vorliegen ${ }^{19}$. Hier ist (wie etwa auch bei den vergleichbaren Regelungen des Ladenschlussgesetzes ${ }^{20}$ ) das Gesetz unter dem Vorbehalt genau festgelegter Änderungsmodalitäten erlassen worden $^{21}$. Wenn das Bundesverfassungsgericht solche und ähnliche Konstellationen für verfassungsgemäß gehalten hat ${ }^{22}$, dann nur, weil die Beschränkung des Geltungsanspruchs des Gesetzes schon in diesem selbst normiert war und sich die Abweichung auf eher marginale Aspekte bezog 23 .

19 Ein Kammerbeschluss des Bundesverfassungsgerichts hat diese Regelung für zulässig erklärt, weil ,die gesetzesverdrängende Wirkung auf einem ausdrücklich zugunsten der Rechtsverordnung reduzierten - subsidiären - Geltungsanspruch des Gesetzes beruht": B VerfG NJW 1998, 669 (670).

20 Das LadSchlG sieht in $\$ 3$ Allgemeine Ladenschlusszeiten und dann in den folgenden Paragraphen Abweichungen davon vor. Gemäß $\S 10,11$ können Landesregierungen durch Rechtsverordnung abweichende Öffnungszeiten für Kur- und Erholungsorte (§ 10) oder für ländliche Gebiete an Sonntagen $(\S 11)$ festlegen, das Bundesministerium für Arbeit und Soziales kann gemäß $\S 12$ durch Rechtsverordnung mit Zustimmung des Bundesrates den Verkauf bestimmter Waren an Sonntagen regeln. Wiederum sieht das Gesetz selbst Abweichungsmöglichkeiten vor, bindet zudem die Rechtsverordnung an tatbestandlich klare Voraussetzungen und verlangt für Rechtsverordnungen des Bundes die Zustimmung des Bundesrates.

21 Weitere Beispiele nennt Kluckert (Fn. 5), § 2 Rn. 138.

22 Neben der Kammer-Entscheidung BVerfG NJW 1998, 669 wird oft eine Senatsentscheidung aus dem Jahre 1958 zitiert: BVerfGE 8, 155. Der Fall betraf eine Frage des Lastenausgleichsgesetzes. Es ging hier zwar nicht um eine Rechtsverordnung, sondern um eine allgemeine Verwaltungsvorschrift, doch ist die Problematik ganz ähnlich gelagert.

23 Im Fall von BVerfGE 8, 155 war im Gesetz selbst eine subsidiäre Regelung zur Abweichung von einzelnen Regeln eben dieses Gesetzes bzw. der auf seiner Grundlage ergangenen Rechtsverordnungen vorgenommen worden, was das Gericht unbeanstandet lässt (BVerfGE 8, 155 [169 ff.]). Ein und derselbe Normgeber hatte also für das von ihm erlassene Gesetz willentlich und gewissermaßen sehenden Auges eine Abweichungsmöglichkeit geschaffen, allerdings nur für eher marginale Fragen des Verwaltungsablaufs, was das Gericht stark herausstellt und deutlich als Grenze markiert (BVerfGE 8, 155 [171]). 
Solche Begrenzungen der Verordnungsmacht sind bei den Ermächtigungen im IfSG nicht ersichtlich. Vor allem fehlt es an dem typischen Merkmal der Fälle zulässiger gesetzesergänzender Rechtsverordnungen: Das Gesetz selbst sieht zum Zeitpunkt seines Erlasses eine solche Delegationsmöglichkeit oder „Anwendungsbeschränkung“ vor. Das ist bei den zahlreichen Gesetzen nicht der Fall, die durch Rechtsverordnung des Gesundheitsministeriums geändert werden könnten. Vielmehr ist das Gesundheitsministerium befugt, auf eine Vielzahl von (teils seit langem in Kraft befindlichen) Gesetzen zuzugreifen und diese zu modifizieren. Das zeigt zugleich, dass es sich nicht lediglich um randständige Aspekte oder technische Details handelt.

Bestimmtheitsgebot (Art. 80 Abs. 1 Satz 2 GG). Ein weiterer Verstoß gegen geltendes Verfassungsrecht tritt hinzu ${ }^{24}$. Er betrifft das Bestimmtheitsgebot des Art. 80 Abs. 1 Satz 2 GG. Danach sind „Inhalt, Zweck und Ausmaß der erteilten Ermächtigung“ im Gesetz zu bestimmen. Literatur wie vor allem die bundesverfassungsgerichtliche Judikatur legen hier relativ strenge Maßstäbe $\mathrm{an}^{25}$. Der Gesetzgeber muss die programmatische Steuerung der Verordnung maßgeblich bestimmen. Im Falle der Ermächtigungen in $\S 5$ Abs. 2 IfSG kann indes von einer erkennbaren Begrenzung im Hinblick auf ihren Inhalt oder ihr Ausmaß keine Rede sein. Ganz unklar ist schon der Kreis der Gesetze, die von der Änderungsermächtigung erfasst werden. Eine einschlägige Ausarbeitung der Wissenschaftlichen Dienste des Deutschen Bundestages hatte ausdrücklich festgestellt, dass hier Abweichungen ,von einer unüberschaubaren Zahl an gesetzlichen Vorschriften“ ermöglicht werden ${ }^{26}$. Damit handelt es sich um eine Art von „Blankovollmacht“27. Das ist das Gegenteil dessen, was das Bestimmtheitsgebot des Art. 80 GG bezweckt.

Änderung der Rechtslage durch die Novelle vom November 2020. Durch das Gesetz vom November $2020^{28}$ wurde die besonders problematische ${ }^{29}$ Verordnungsermächtigung des $\S 5$ Abs. 2 Nr. 3 IfSG gestrichen. Unangetastet blieben aber die Verordnungsermächtigungen der Nr. 4, 7, 8 und 10. Die dargelegten Einwände gegen ihre Verfassungsmäßigkeit bestehen somit ungeschmälert fort.

24 Beide Punkte werden in der Diskussion nicht immer klar auseinandergehalten. Der soeben behandelte normenhierarchische Einwand bliebe bestehen, selbst wenn es der ermächtigenden Gesetzesnorm nicht an der gebotenen Bestimmtheit fehlen würde - was allerdings der Fall ist, wie sogleich gezeigt wird.

25 Vgl. statt vieler die Darstellung von Hartmut Bauer In: Dreier, GGK II (Fn. 16), Art. 80 Rn. $32 \mathrm{ff}$.

26 Wissenschaftliche Dienste des Bundestages, Ausarbeitung v. 2. April 2020, WD $3-3000$ - 080/20, S. 6. - Ähnlich Rixen: Gesundheitsschutz (Fn. 4), S. 1102: „Die Rechtsverordnungen ermöglichen zahlreiche Modifikationen und vor allem Ausnahmen praktisch im gesamten öffentlich-rechtlichen Recht der Gesundheit“".

27 Thomas Kingreen: Das Studium des Verfassungsrechts in der Pandemie, In: Jura, S. 10191035 (1034) (2020).

28 Vgl. oben Fn. 1.

29 Guckelberger: Abänderung (Fn. 18), S. 1444 ff. 


\section{Föderalismus}

\subsection{Zur Kritik an der bundesstaatlichen Struktur}

Die föderale Struktur der Bundesrepublik Deutschland kann auf eine lange Historie zurückblicken und ist im Grundgesetz fest verankert ${ }^{30}$. Die sogenannte Ewigkeitsgarantie des Art. 79 Abs. 3 GG, die bestimmte Materien vor einer Verfassungsänderung schützt und somit auch dem Zugriff noch so großer Mehrheiten entzieht, garantiert die bundesstaatliche Struktur gleich mehrfach $^{31}$. Von daher muss es irritieren, wenn im Zuge der Corona-Debatten von der föderalen Vielfalt der Bundesrepublik zumeist in einem negativen und pejorativen Sinn die Rede gewesen ist. Ständig wurde in den Medien der vermeintliche „Flickenteppich“ an Regelungen kritisiert, verbunden mit ganz ahistorischen Hinweisen auf eine angeblich herrschende „Kleinstaaterei“ und dem Ruf nach bundeseinheitlichen Regelungen. Offenkundig macht sich hier ein ,,antiföderaler Reflex“ bemerkbar ${ }^{32}$, den man auch aus anderen Kontexten (Schulen, Universitäten) kennt.

Demgegenüber ist daran zu erinnern, dass die föderale Gliederung nicht allein aufgrund der dadurch erzielten vertikalen Gewaltenteilung einen freiheitssichernden Effekt hat, sondern auch regional problemangemessene Regelungen ermöglicht. Derartige situationsspezifische und deswegen zwingend unterschiedlich ausfallende Maßnahmen sind auch in der Corona-Krise ergriffen worden, in der sich das Infektionsgeschehen lange Zeit sehr unterschiedlich entfaltete, wenn man nur an die gravierenden Differenzen zwischen Bayern und Mecklenburg-Vorpommern denkt.

Gewiss verdankten sich die divergierenden Regelungen nicht immer unterschiedlichen Sachlagen, sondern spielten auch andere, vornehmlich politische Faktoren (Parteienkonkurrenz, Profilierungsversuche) eine Rolle. Und selbstverständlich waren die ergriffenen Maßnahmen nicht gänzlich frei von Inkonsistenzen und zuweilen auch von Kuriositäten. Besonders wünschenswert wäre es gewesen, wenn man immer relativ streng zwischen den entscheidenden Kriterien für die Bekämpfung der Pandemie (also welche Parameter sind entscheidend: zum Beispiel R-Wert, Inzidenzwerte, Infektionszahlen, Krankenzahlen, Verfügbarkeit von Krankenbetten) und den aufgrund der Anwendung dieser Kriterien ergriffenen Maßnahmen selbst unterschieden (und das auch beständig so kommuniziert) hätte. Dadurch hätte sich die Akzeptanz so mancher Entscheidung wohl steigern lassen.

Aber davon abgesehen erscheint es eben nicht nur zulässig, sondern geradezu geboten, auf bestehende Divergenzen mit unterschiedlichen Maßnahmen zu reagieren. Die bundesstaatliche Struktur bietet hierzu aufgrund der Eigenständigkeit der Länder beste Voraussetzungen und erlaubt zudem, wenn auch in recht engen Grenzen, ein

30 Umfassende Darstellung: Josef Isensee: Idee und Gestalt des Föderalismus im Grundgesetz, In: Josef Isensee/Paul Kirchhof (Hrsg.), Handbuch des Staatsrechts der Bundesrepublik Deutschland, Bd. VI, 3. Aufl., § 126 (S. 3-199) Heidelberg (2008).

31 Vgl. Horst Dreier In: ders., GGK II (Fn. 16), Art. 79 III Rn. 21 ff., 47 f.

32 Kersten/Rixen: Verfassungsstaat (Fn. 2), S. 113. 
konkurrierendes Ringen um die beste Problemlösung ${ }^{33}$. So kann es im Grunde nicht überraschen, dass nach der Einschätzung vieler Beobachter, nicht zuletzt solcher aus dem Ausland, Deutschland bei der Bekämpfung der Pandemie gerade wegen seiner föderalen Struktur bislang im Vergleich besser abgeschnitten hat als zentralistische Staaten wie Frankreich oder Großbritannien ${ }^{34}$.

\subsection{Das Problem des bundesstaatlichen Zugriffs auf Verwaltungskompetenzen der Länder}

Ein verfassungsrechtliches Problem ergibt sich nicht aus der Eigenständigkeit der Länder, sondern umgekehrt aus der Gefährdung ihrer Kompetenzen durch eine übergriffige Regelung des $§ 5$ IfSG in seiner im März 2020 geänderten Fassung ${ }^{35}$. Hier werden nämlich dem Bundesgesundheitsministerium Verwaltungskompetenzen zugestanden, die die Ausführung des Gesetzes betreffen, indem ihm in mehreren Fällen die Befugnis zur „Anordnung“36 bestimmter Maßnahmen erteilt wird ( $\$ 5$ Abs. 2 Nr. 1, 2, 5 und 6). Für eine derartige Verwaltungskompetenz des Bundes bedürfte es aber einer Verankerung im Grundgesetz, an der es fehlt, weil es für das Infektionsschutzgesetz weder geschriebene noch ungeschriebene Verwaltungszuständigkeiten des Bundes gibt.

Die doppelte Vermutung des Art. 83 GG. Der bundesdeutsche Föderalismus ist ein sogenannter Exekutivföderalismus. Das heißt: Während im Bereich der Gesetzgebung eindeutig der Bund dominiert, resultiert die Stärke der Länder daraus, dass sie nicht nur die eigenen Landesgesetze, sondern - von einigen Ausnahmen abgesehen auch die Bundesgesetze ausführen (Art. 83 ff. GG). Art. 83 GG enthält für diesen Regelfall eine doppelte Vermutung: Erstens, dass die Länder die Bundesgesetze ausführen (und nicht der Bund). Zweitens, dass sie sie als eigene Angelegenheit ausführen (und nicht im Auftrag des Bundes). „Widerlegt“" wird die erste Vermutung in den Fällen der bundeseigenen Verwaltung (Art. 86 GG), die zweite in den Fällen der Bundesauftragsverwaltung (Art. $85 \mathrm{GG}$ ).

Doch liegt weder der eine noch der andere Ausnahmefall vor. Das Infektionsschutzgesetz gehört vielmehr zu den Gesetzen, die gemäß Art. 83, 84 GG von den Ländern als eigene Angelegenheit ausgeführt werden. Zwar sind auch hier einige Ingerenzmöglichkeiten des Bundes vorgesehen, doch sind diese eng begrenzt. So kann der Bund in Ausnahmefällen, ,wegen eines besonderen Bedürfnisses nach bundeseinheitlicher Regelung das Verwaltungsverfahren ohne Abweichungsmöglichkeit für die Länder" regeln (Art. 84 Abs. 1 Satz 5 GG); auch kann die

33 So auch Oliver Lepsius: Grundrechtsschutz in der Corona-Pandemie, In: Recht und Politik 56, S. 258-282 (278 f.), (2020), mit dem treffenden zusätzlichen Hinweis, dass schon wegen der Möglichkeit von alternativen Regelungen der Rechtfertigungsdruck wächst.

34 Dazu einige Hinweise bei Nathalie Behnke: Föderalismus in der (Corona-)Krise?, In: Aus Politik und Zeitgeschichte, 70. Jg., Heft 35-37, S. 9-15 (9, 14) (2020).

35 Vgl. oben Fn. 4.

36 Hierunter sind entweder Einzelverfügungen (Verwaltungsakte) oder Allgemeinverfügungen $\mathrm{zu}$ verstehen. 
Bundesregierung mit Zustimmung des Bundesrates allgemeine Vorschriften erlassen (Art. 84 Abs. 2 GG); sie führt zudem eine allgemeine Rechtsaufsicht (Art. 84 Abs. 3 GG). In keinem dieser Fälle sind dem Bund aber eigene Vollzugskompetenzen verliehen. Das gilt auch für Art. 84 Abs. 5 GG, wonach der Bundesregierung durch ein Bundesgesetz, das wiederum der Zustimmung des Bundesrates bedarf, „die Befugnis verliehen werden [kann], für besondere Fälle Einzelweisungen zu erteilen“, die im Falle der Dringlichkeit an die obersten Bundesbehörden zu richten sind.

Ausführung durch das Gesundheitsministerium? Das bedeutet: Die in $\S$ 5 Abs. 2 Nr. 1, 2, 5 und 6 IfSG enthaltenen Ermächtigungen des Gesundheitsministeriums, Anordnungen zu erteilen und das IfSG somit ,auszuführen“, sind durch das Grundgesetz nicht gedeckt. Weder handelt es sich bei den „Anordnungen“ gemäß $\S 5$ Abs. 2 Nr. 1, 2, 5 und 6 IfSG um die Regelung des Verwaltungsverfahrens noch um allgemeine Verwaltungsvorschriften, die Ausübung der Rechtsaufsicht oder Einzelweisungen für besondere Fälle. Vielmehr sind dem Gesundheitsministerium direkte Verwaltungskompetenzen zugewiesen, insbesondere der Erlass von Verwaltungsakten. Die genannten Normen erlauben, was das Grundgesetz für den hier vorliegenden Fall der Ausführung eines Bundesgesetzes durch die Länder als eigene Angelegenheit gerade nicht gestattet: die Wahrnehmung von Verwaltungskompetenzen durch eine Bundesbehörde ${ }^{37}$.

„Ungeschriebene“ ${ }^{6}$ Verwaltungszuständigkeit? Als letzter Notanker bliebe die Möglichkeit, die Anordnungsbefugnisse auf eine „ungeschriebene“ Verwaltungszuständigkeit des Bundes zu stützen ${ }^{38}$. Auch wenn diese Figur in der Rechtswissenschaft nicht von vornherein als unzulässig angesehen wird, so muss ihre Heranziehung doch ein ebenso evidenter wie seltener Ausnahmefall bleiben. Der Hinweis auf eine -erwünschte oder rein subjektiv für notwendig gehaltene - einheitliche Ausführung der Bundesgesetze reicht keinesfalls hin. Es kommen vielmehr nur jene seltenen Ausnahmefälle in Betracht, in denen der Zweck eines Bundesgesetzes durch ein Verwaltungshandeln der Länder überhaupt objektiv nicht erreicht werden kann ${ }^{39}$ oder es für eine Landeskompetenz an jeglichem Anknüpfungspunkt fehlt ${ }^{40}$. Beides trifft für die in $\S 5$ Abs. 2 IfSG eingeräumten Anordnungsvollmachten ersichtlich nicht $\mathrm{zu}^{41}$. Diese Vorschriften verstoßen also gegen Art. 83, 84 GG.

37 Wie hier Josef Franz Lindner, Öffentliches Recht, In: Hubert Schmidt (Hrsg.), COVID-19. Rechtsfragen zur Corona-Krise, München (2020), § 16 Rn. 16 ff.; Kersten/Rixen, Verfassungsstaat (Fn. 2), S. 125 ff. - Auch lässt sich die Verwaltungskompetenz des BMG nicht auf Art. 87 Abs. 3 Satz 1 GG stützen; dazu die Ausarbeitung der Wissenschaftlichen Dienste des Deutschen Bundestages: WD 3-3000-111/20 mit Nachweisen der Kommentar-Literatur.

$38 \mathrm{Zu}$ dieser Figur Georg Hermes, In: Horst Dreier (Hrsg.), Grundgesetz-Kommentar, Bd. III, 3. Aufl., Tübingen (2018), Art. 83 Rn. 39 ff.

39 So BVerfGE 41, 291 (312).

40 Hermes (Fn. 38), Art. 83 Rn. 43, 44; siehe die dort genannten singulären Fallgestaltungen. Aus der Judikatur: BVerfGE 11, 6 (17); 22, 180 (216 f.).

41 Kersten/Rixen, Verfassungsstaat (Fn. 2), S. 126 f.; Kingreen, Studium (Fn. 27), S. 1032. 
Änderung der Rechtslage durch die Novelle vom November 2020. Durch das Gesetz vom November $2020^{42}$ wurden die hier interessierenden Nr. 1 und 2 des $\S 5$ Abs. 2 IfSG gestrichen, nicht aber die bisherigen Nr. 5 und 6. Die dargelegten verfassungsrechtlichen Bedenken bleiben insofern ungeschmälert bestehen.

\section{Demokratie}

In der strikt repräsentativ ausgestalteten demokratischen Ordnung des Grundgesetzes $^{43}$ richtet sich der Blick zentral auf die Handlungshoheit des Bundestages. Denn er ist das einzige Organ, das im Wahlakt direkt vom Volk legitimiert ist, und verfügt insofern über einen Legitimationsvorsprung und hat neben anderen wichtigen Funktionen wie der Wahl und der Kontrolle der Regierung die Gesetzgebungsgewalt inne. Bei der Frage, ob das Parlament seiner verfassungsrechtlichen Schlüsselstellung in der Pandemie gerecht geworden ist, sind drei Aspekte zu unterscheiden: die Handlungsfähigkeit des Bundestages, seine Handlungswilligkeit und die bestehenden Handlungsmöglichkeiten.

Handlungsfähigkeit des Bundestages. Auf dem ersten Höhepunkt der Pandemie stellte sich die Frage, wie in einem Bundestag von über 700 Abgeordneten ein regulärer parlamentarischer Betrieb aufrechterhalten werden könnte. Überlegungen namentlich des Bundestagspräsidenten, im Grundgesetz eine Art von Notparlament in Analogie zu Art. 53a GG zu verankern, blieben bislang Episode ${ }^{44}$. Man beschritt einen pragmatischeren Weg und reduzierte durch eine Änderung der Geschäftsordnung des Bundestages die Beschlussfähigkeit von der Hälfte auf ein Viertel der Mitglieder ${ }^{45}$. Außerdem wurden zusätzliche Wahlurnen außerhalb des Plenarsaals aufgestellt. Schließlich gab es offenbar eine informelle pairing-Absprache zwischen den Fraktionen, die dazu führt, dass für jeden fehlenden Abgeordneten der Regierungsfraktionen zum Ausgleich einer der Opposition den Verhandlungen fernbleibt, um so bei geringerer Besetzung die Stärkeverhältnisse abzubilden ${ }^{46}$. Auch an weitere Maßnahmen ließe sich denken: Etwa an hybride Sitzungen, an denen potenziell alle

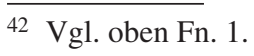

43 Zur Struktur und Ausprägung des Demokratieprinzips im Grundgesetz: Horst Dreier, In: ders., GGK II (Fn. 16), Art. 20 (Demokratie), Rn. 82 ff., 93 ff., 109 ff. - Monographisch Quirin Weber: Parlament - Ort der politischen Entscheidung?, Basel (2011).

44 Für eine solche Einrichtung mit Vorschlag einer entsprechenden Grundgesetz-Änderung (Einfügung eines neuen Art. 53b GG, der Vorkehrungen der Art. 53a Abs. 1, 115e-h GG kombiniert): Tilman Hoppe/Horst Risse: Das wahre Parlament erkennt man in der Not, In: DVB1. S. 1386-1389 (2020).

45 § 126a GeschO-BT, eingeführt durch Beschluss v. 25. März 2020 (BGB1. I S. 764); hier sind auch für Sitzungen der Ausschüsse und für Anhörungen besondere Regelungen getroffen. Die Änderung wurde zunächst bis zum 30. September, durch Beschluss vom 17. September 2020 (BGB1. I S. 2067) bis zum 31. Dezember 2020 befristet.

46 Zur verfassungsrechtlichen Problematik des Verfahrens Kersten/Rixen: Verfassungsstaat (Fn. 2), S. $101 \mathrm{ff}$. 
Abgeordneten teilnehmen könnten, wie man das in Großbritannien und im EU-Parlament praktiziert hat ${ }^{47}$.

Alles in allem besteht an der prinzipiellen Handlungsfähigkeit des Bundestages kein Zweifel. Wie aber steht beziehungsweise stand es um seine Handlungswilligkeit?

Handlungswilligkeit des Bundestages. Hier fällt die Diagnose deutlich negativer aus. Der Bundestag hat sich lange Zeit offenbar nicht in der Lage gesehen, die ganz außergewöhnliche gesellschaftliche und politische Gesamtlage in einer angemessenen Weise zu thematisieren oder gar mit entschiedenen Gesetzgebungsakten zu steuern. Die Pandemiebekämpfung erschien nicht nur in den Augen der Öffentlichkeit, sondern auch bei verfassungsrechtlicher Betrachtung als Sache und Aufgabe der Exekutiven von Bund und Ländern. Parlamente als zentrale Orte der Demokratie kamen praktisch kaum vor ${ }^{48}$. An einer großen Debatte zu der das ganze Land bewegenden Frage, ob und inwiefern die nie dagewesenen Einschnitte in das öffentliche Leben und die vorbildlosen Einschränkungen der Grundrechte gerechtfertigt sind, hat es über viele Monate gefehlt - manche fühlten sich nicht von ungefähr an die Flüchtlingskrise von 2015 erinnert, wo es ebenfalls keine eingehende Diskussion im Bundestag über das pro und contra der Regierungspolitik gegeben hat ${ }^{49}$.

Das ist nicht lediglich ein Schönheits- oder Formfehler. Denn dem Parlament als Gravitationszentrum der Demokratie kommt auch die Aufgabe zu, als Forum der Nation für alle die Menschen bewegenden Themen aufzugreifen, in aller Regel kontrovers zu diskutieren und Handlungsalternativen vorzustellen. Eine solche Debatte kam spät und vielleicht zu spät - Ende Oktober und nochmals Mitte November 2020, somit acht Monate nach Ausbruch der Pandemie und sieben Monate nach dem ersten Lockdown ${ }^{50}$. Bis dahin sind zwar viele gesetzgeberische Maßnahmen sozial-, finanz-, medizin- und wirtschaftsrechtlicher Art im Zusammenhang mit der Pandemie ergriffen worden, aber das eigentliche Feld ihrer Bekämpfung mit all den einschneidenden Maßnahmen für Wirtschaft, Kultur, Schulen, Kitas, Universitäten und das private Leben überließ man weitestgehend der Exekutive. Einen einzigen „Sieg“ konnte der Bundestag erringen: Die Entscheidung über das Vorliegen (und das Ende) einer epidemischen Lage von nationaler Tragweite gemäß $§ 5$ Abs. 1 IfSG obliegt ihm und nicht, wie zunächst vorgesehen, der Bundesregierung ${ }^{51}$.

Ansonsten aber hat sich die Bekämpfung der Corona-Pandemie lange Zeit allein als Sache der Exekutive dargestellt: besonders der Ministerpräsidenten der Länder in

47 Siehe Stefan Marschall: Parlamente in der Krise? Der deutsche Parlamentarismus und die Corona-Pandemie, In: Aus Politik und Zeitgeschichte, 70. Jg., Heft 35-37, S. 11-17 (15) (2020).

48 Zurecht beklagt von vielen Stimmen; stellvertretend Volkmann: Verordnungsregime (Fn. 9), S. 3159.

49 Vgl. Horst Dreier: Vom Schwinden der Demokratie, In: Friedrich Wilhelm Graf/Heinrich Meier (Hrsg.), Die Zukunft der Demokratie. Kritik und Plädoyer, S. 29-81 (70 f.). München (2018).

50 Siehe unten bei und in Fn. $54 \mathrm{f}$.

51 Michael Fuchs: „Gesundheitsdiktatur“ und „Legiszid“, In: DÖV, S. 653-659 (654), (2020); Rixen: Gesundheitsschutz (Fn. 4), S. 1102. 
entsprechenden, medial gehypten „Runden“ unter demonstrativer (nur phasenweise einmal geschwächter) Führung der Kanzlerin, die zumeist auch in den anschließenden Pressekonferenzen im Zentrum des Interesses stand. Dieser Kreis, von dem das Grundgesetz nichts weiß, ist im Übrigen auch etwas anderes als der seit langem bestehende informelle Kreis der Ministerpräsidentenkonferenz. Der wichtigste und schädlichste Nebeneffekt dieser Verlagerung der Entscheidungen auf die Exekutive besteht im Fehlen dessen, was eine parlamentarische Beratung gerade ermöglichen soll: dem Austausch von Argumenten, dem Vortragen von Begründungen, der Gegenüberstellung kontroverser Positionen ${ }^{52}$. Den Regierungsfraktionen fehlte es über ein halbes Jahr lang am Bestreben, insbesondere bei der Fixierung der grundrechtseinschränkenden Maßnahmen der zentralen Rolle des Bundestages gebührend Rechnung zu tragen ${ }^{53}$. Sie mögen sich wieder einmal weniger als Sachwalter der Belange und Rechte des Parlaments und mehr als verlängerter Arm der Regierung verstanden haben. Verräterisch kann schon die Sprache sein, wenn etwa von einer „Mitsprache“ oder „Beteiligung“ des Bundestages die Rede ist. Denn der Bundestag hat nicht um Mitsprache oder Beteiligung an Entscheidungen zu bitten, die im Kern andere treffen - er selbst hält die volle gesetzliche Entscheidungsmacht in der Hand. Er muss nur den Willen haben, diese Macht zu nutzen.

Ein Stück weit sind die genannten Defizite im Herbst 2020 behoben worden: Es gab eine Regierungserklärung der Kanzlerin, auf die eine Generaldebatte im Bundestag folgte ${ }^{54}$. Später wurde das Dritte Gesetz, ,zum Schutz der Bevölkerung bei einer epidemischen Lage von nationaler Tragweite" 55 verabschiedet, mit dem vor allem eine lange Liste von Regelbeispielen verankert, Maßnahmen gemäß ihrer Schwere an Inzidenzwerte geknüpft und Tatbestandsvoraussetzungen durch die Benennung bestimmter Voraussetzungen für die Feststellung einer ,epidemischen Lage von nationaler Tragweite" fixiert wurden ${ }^{56}$.

Handlungsmöglichkeiten des Bundestages. Der Fall der Gesetzesnovelle vom November 2020 zeigt bereits, dass es dem Bundestag an Handlungsmöglichkeiten durchaus nicht fehlt. Zwar mag man der zentralen neuen Norm ( $\$ 28 \mathrm{a}$ IfSG) vorwerfen, sie wiederhole mit der Auflistung von Regelbeispielen nur die bislang in Gestalt von Rechtsverordnungen erlassenen Maßnahmen auf einer höheren Normebene. Doch abgesehen davon, dass das nicht die einzige Neuerung ist, kommt der Norm schon wegen ihrer Gesetzesqualität ein demokratischer Mehrwert und eine wichtige Legitimationsfunktion zu. Denn angesichts der Schwere der Grundrechtseingriffe ist es ein verfassungsrechtliches Gebot, dass das vom Volk unmittelbar

52 Talkshow-Runden mit Bundesministern oder Ministerpräsidenten oder Podcasts der Kanzlerin sind natürlich kein tauglicher Ersatz.

$53 \mathrm{Zu}$ den verschiedenen, aber ohne Mehrheit gebliebenen Initiativen der Opposition siehe Fuchs: Gesundheitsdiktatur (Fn. 51), S. 657 mit Fn. 33.

54 186. Sitzung des Deutschen Bundestages vom 29. Oktober 2020; nachzulesen im Plenarprotokoll 19/186, S. $23351 \mathrm{ff}$.

55 Vgl. Fn. 1. Zur Debatte siehe dazu das Plenarprotokoll des Deutschen Bundestages 19/191 vom 18. November 2020, S. $24045 \mathrm{ff}$.

$56 \mathrm{Vgl}$. dazu oben unter Punkt 2.1. 
legitimierte Parlament und nicht die Exekutive die Abwägung der gegenläufigen Interessen vornimmt und die zentralen Kriterien für die Ergreifung der spezifischen infektionsschutzrechtlichen Maßnahmen festlegt. Aber natürlich kann die gesetzliche Regelungsdichte durchaus noch enger, der Takt einschlägiger gesetzlicher Vorgaben durchaus noch höher werden. Unser Nachbarland Österreich hat bewiesen, dass das keine Utopie ist ${ }^{57}$. Dort ist durch eine kontinuierliche Gesetzgebungstätigkeit gerade auf dem Gebiet der Festlegung bestimmter Maßnahmen zur Bekämpfung der Ausbreitung von COVID-19 das Parlament der maßgebliche und verantwortliche Akteur geblieben $^{58}$.

Schließlich sei festgehalten, dass der Bundestag nicht auf den Erlass materiellrechtlicher Gesetzesnormen beschränkt ist. So wäre es - auch das zeigt das österreichische Beispiel - durchaus denkbar, das Inkrafttreten von exekutiven Rechtsverordnungen von parlamentarischen Zustimmungsvorbehalten abhängig zu machen oder das Parlament mit entsprechenden Aufhebungsbefugnissen auszustatten ${ }^{59}$. Ein in diese Richtung gehender Vorschlag wurde von der Fraktion Bündnis 90/Die Grünen im Mai 2020 unterbreitet $^{60}$. Man könnte ihn vielleicht noch einmal auf die Tagesordnung setzen und dabei flankierende Berichts- und Transparenzpflichten der Exekutive verlangen. Wie gesagt: Der Bundestag hat es in der Hand. Einige Schritte in die richtige Richtung ist man mit der Gesetzesnovelle begrüßenswerterweise gegangen ${ }^{61}$. Die Verankerung eines Zustimmungsvorbehaltes für die Rechtsverordnungen des Bundesgesundheitsministerium oder einer Befugnis zu ihrer Aufhebung ist nach Pressemeldungen am Widerstand der CDU-Fraktion gescheitert ${ }^{62}$.

57 Siehe etwa die folgenden drei umfänglichen Gesetze, die nach Ausbruch der Pandemie im März und Anfang April 2020 ergangen sind: „COVID-19 Gesetz“ (Bundesgesetzblatt für die Republik Österreich, Teil I, ausgegeben am 15. März 2020, Nr. 12); „2. COVID-19 Gesetz“ (Bundesgesetzblatt für die Republik Österreich, Teil I, ausgegeben am 21. März 2020, Nr. 16); ,3. COVID-19 Gesetz“ (Bundesgesetzblatt für die Republik Österreich, Teil I, ausgegeben am 4. April 2020, Nr. 23).

58 Nur nebenbei sei angemerkt, dass auch die Landesparlamente, die völlig in den Hintergrund getreten sind, als Akteure eine sehr viel stärkere Stellung einnehmen könnten. Art. 80 Abs. 4 GG sieht ausdrücklich vor, dass dann, wenn Landesregierungen aufgrund von Bundesgesetzen zum Erlass von Rechtsverordnungen ermächtigt werden, den Ländern das Recht zusteht, entsprechende Regelungen durch Gesetz zu erlassen. Art. 80 Abs. 4 GG wurde 1994 eingeführt mit der ausdrücklichen Zielsetzung, die Handlungsmöglichkeiten der Landesparlamente zu stärken (Bauer [Fn. 16], Art. 80 Rn. 7, 67 ff.).

59 Zur verfassungsrechtlichen Zulässigkeit solcher Instrumente nur Bauer (Fn. 16), Art. 80 Rn. $27 \mathrm{ff}$.

60 BT-Drs. 19/18.958, S. 3 f. Siehe auch die Auflistung der (allesamt abgelehnten) Anträge der Oppositionsfraktionen aus dem November 2020 in: BT-Drs. 19/24.334, S. 1 ff. (zu den Beschlussempfehlungen S. 6 ff., zum Beratungsverlauf S. 74 ff.).

61 Vgl. oben unter 2.1.; 2.2; 3.2.

62 Alexander Haneke: Solidität und Eile, in: FAZ Nr. 268 v. 17. November 2020, S. 2. 


\section{Grundrechte}

\subsection{Geltungskraft und Einschränkungen}

Die im Zuge der Bekämpfung der Corona-Pandemie ergriffenen grundrechtseinschränkenden Maßnahmen sind in Umfang, Breite und Tiefe historisch einmalig, ohne Beispiel und ohne Vorbild ${ }^{63}$. Noch niemals in der Geschichte der Bundesrepublik sind für so viele Menschen so viele Grundrechte für einen so langen Zeitraum in denkbar weitem Umfang eingeschränkt worden. Allerdings sollte man vorsichtig mit der Redeweise von der Suspension der Grundrechte sein. Denn das hieße: temporäre Außerkraftsetzung der Grundrechte, also vollständiger Entfall ihrer Geltungskraft. Eine solche Vorstellung lag dem berühmt-berüchtigten Notstandsartikel des Art. 48 Abs. 2 der Weimarer Reichsverfassung von 1919 zugrunde. Dieser Norm gemäß konnte der Reichspräsident zur Wiederherstellung der öffentlichen Sicherheit und Ordnung verschiedene, im einzelnen aufgeführte Grundrechte ,ganz oder zum Teil außer Kraft setzen“. Behörden und Gerichte waren bei ihren Entscheidungen also durch die suspendierten Grundrechte nicht mehr gebunden ${ }^{64}$.

Doch eine solche Vorstellung ist dem Grundgesetz fremd, und zu einer derartigen Außerkraftsetzung ist es in der Corona-Pandemie nicht gekommen. Schlagender Beweis: Bei den vielen gerichtlichen Anfechtungen der Maßnahmen (etwa der Demonstrationsverbote) wurden die jeweils betroffenen Grundrechte (etwa Art. 8 GG) von den Gerichten als Maßstab für die Prüfung der Verfassungsmäßigkeit der Maßnahmen explizit herangezogen. Das wäre gar nicht möglich gewesen, wenn die Grundrechte zum Zeitpunkt der Entscheidungen ganz außer Kraft gesetzt und in diesem Sinne ,suspendiert“ gewesen wären. Der Staat ist von der Beachtung der Grundrechte also nicht befreit.

Aber dennoch ist natürlich das gewaltige Ausmaß der Reduzierung grundrechtlich geschützter Freiheiten und Tätigkeiten ohne Beschönigung zu konstatieren: Ausgangsbeschränkungen und Kontaktverbote, Versammlungsverbote und die Schließung von Hotels, Gaststätten, Theatern, Opern und anderen Kultureinrichtungen, das Verbot von Zusammenkünften in Vereinen, Bildungsanstalten sowie in Kirchen, Moscheen und Synagogen sowie die partielle oder komplette Schließung von Betriebs-, Produktions- oder Verkaufsstätten, dazu Einreiseverbote und Ausreisegebote in bestimmte bzw. aus bestimmten Regionen oder Bundesländern - dies alles deckt so gut wie den kompletten Grundrechtskatalog des ersten Abschnitts des Grundgesetzes ab: Freiheit der Person (Art. 2 Abs. 2 GG), Religionsfreiheit (Art. 4 GG), Kunst- und Wissenschaftsfreiheit (Art. 5 Abs. 3 GG), Ehe und Familie (Art. 6 GG), Versammlungs- und Vereinigungsfreiheit (Art. 8,9 GG), Freizügigkeit (Art. 11 GG), Berufs- und Eigentumsfreiheit (Art. 12,14 GG). Das ist ein beeindruckender, besser vielleicht bedrückender, geradezu bedrohlich wirkender Katalog.

63 Das ist in Literatur und Judikatur immer wieder zutreffend festgestellt worden; Nachweise bei Kluckert (Fn. 5), § 2 Rn. 105.

64 Siehe die Erläuterung von Gerhard Anschütz: Die Verfassung des Deutschen Reichs vom 11. August 1919, 14. Aufl., Anm. 15 zu Art. 48 (S. 289) Berlin (1933). 
Waren beziehungsweise sind diese umfangreichen Beschränkungen gerechtfertigt und verfassungsrechtlich überhaupt zulässig? Waren sie tatsächlich nötig? Oder waren sie womöglich noch nicht streng genug beziehungsweise sind zwischenzeitlich erfolgte Lockerungen ihrerseits $\mathrm{zu}$ weit gegangen? Wo liegt das richtige Maß - und wer bestimmt es? Das ist die zentrale Problematik, die im letzten Dreivierteljahr unermüdlich auf allen Kanälen und unzähligen Foren, in allen denkbaren Formaten, in Presse, Funk und Fernsehen, den sozialen Medien, der Politik, dem Familien- und Freundeskreis diskutiert worden ist. Und nicht nur das. Es hat auch eine rasch ansteigende Flut von gerichtlichen (meist: verwaltungsgerichtlichen) Entscheidungen gegeben, deren Anzahl mittlerweile bei mehreren tausend liegen dürfte ${ }^{65}$. Und die Gerichte haben getan, was Gerichte eben tun: Sie haben entschieden. Manchmal haben sie die Maßnahmen für rechtmäßig, manchmal für rechtswidrig befunden, und natürlich gab es zu sachlich identischen Maßnahmen auch unterschiedliche Auffassungen: nicht nur im Instanzenzug, sondern auch im Verhältnis der Oberverwaltungsgerichte der Länder zueinander. Diese Judikatur zu sichten, $\mathrm{zu}$ systematisieren und analysierend einzuordnen, ist hier nicht der Ort ${ }^{66}$. Vielmehr finden sich im Folgenden einige Kernaussagen zum Stellenwert des Lebens- und Gesundheitsschutzes sowie des Abwägungsgebotes, bevor das überragend wichtige Verhältnismäßigkeitsprinzip in seiner Struktur und Funktionsweise dargestellt und am Schluss auf das Problem der nicht-intendierten Nebenfolgen hingewiesen wird.

\subsection{Art. 2 Abs. 2 GG: kein Super- oder Obergrundrecht}

Manche Äußerungen in der Öffentlichkeit erweckten den Eindruck, der in Art. 2 Abs. 2 GG verankerte Schutz von Leben und Gesundheit stelle eine Art von Oberoder Supergrundrecht dar, das allen anderen Grundrechten und sonstigen Belangen prinzipiell vorgehe und sich sozusagen von Haus aus gegen andere Rechtsgüter wie selbstverständlich durchsetze ${ }^{67}$. Eine solche Vorstellung geht aber aus verfassungsrechtlicher Sicht komplett in die Irre. Dass das Recht auf Leben und körperliche Unversehrtheit nicht absolut gilt, kann man schon an dem Gesetzesvorbehalt erkennen, dem es unterliegt. Es kann also eingeschränkt werden. Zudem suggeriert die Vorstellung eines ,absoluten“ Grundrechts die Existenz einer Art von Grundrechtshierarchie. Eine solche starre, allgemeine Hierarchie im Sinne einer

65 Auf der Homepage: www.dejure.org gibt es eine eigenständige Rubrik zu COVID 19. Hier sind (ohne Anspruch auf Vollständigkeit) einschlägige Entscheidungen, nach Gerichten oder Rechtsgebieten geordnet, aufgeführt. Mittlerweile (22. November 2020) handelt es sich um über 1800 Judikate.

66 Kursorischer Überblicke bei Lepsius: Grundrechtsschutz (Fn. 33), S. 273 ff.; Volkmann: Verordnungsregime (Fn. 9), S. 3154 ff.

67 Dagegen auch Kingreen: Studium (Fn. 27), der auf S. 1027 davon spricht, es sei ,der irreführende Eindruck erweckt worden, Leben und körperliche Unversehrtheit seien allen Freiheitsrechten vorgeordnet und der staatliche Schutzauftrag rechtfertige jegliche Eingriffe in Freiheitsrechte“, um fortzufahren: „Verfassungsrechtlich ist die Behauptung ,Leben und Gesundheit über alles" nämlich schlicht falsch.“" 
Wertordnung gibt es aber nicht - auch nicht zwischen Grundrechten, die einen expliziten Eingriffsvorbehalt kennen, und solchen, die vorbehaltlos (aber eben auch nicht schrankenlos) gewährleistet $\operatorname{sind}^{68}$. Die Religionsfreiheit steht nicht a priori höher als die Berufsfreiheit, die Kunstfreiheit nicht höher als oder niedriger als Meinungs- und Pressefreiheit. „Keines der Freiheitsrechte, die von den Schutzmaßnahmen betroffen sind, ist a priori abwägungsfest und einschränkungsgefeit." 69

\subsection{Abwägungsgebot}

Mit dem Hinweis auf die Abwägung ist der zentrale Punkt benannt, dass grundrechtseinschränkende Maßnahmen nur dann zulässig sind, wenn sie sich ihrerseits auf bestimmte Rechts- und Verfassungsgüter stützen können. In der Corona-Pandemie sind das vor allem der Gesundheitsschutz der Bürger sowie die Sicherung der Leistungsfähigkeit des Gesundheitssystems. Da es auch bei Rechts- und Verfassungsgütern keine feste Hierarchie gibt, kommt es aber wie stets so auch hier darauf an, zwischen der Freiheitssphäre des Bürgers auf der einen und den für den staatlichen Eingriff streitenden Belangen auf der anderen Seite einen „schonenden Ausgleich“ (Peter Lerche) zu finden bzw. ,praktische Konkordanz“ (Konrad Hesse) herzustellen. Es bedarf also einer Abwägung zwischen den Rechtsgütern. Das Ergebnis einer solchen Abwägung steht dabei nicht aufgrund einer vermeintlich fixierten Werteoder Grundrechtshierarchie von vornherein fest, sondern kristallisiert sich erst in der jeweiligen Konstellation heraus, muss also erst argumentativ gefunden werden. Allerdings funktioniert das nicht dergestalt, dass man im unmittelbaren Zugriff das Gewicht der Gründe, die für den staatlichen Eingriff sprechen, mit dem Freiheitsinteresse der Bürger direkt abgleicht. Das Instrumentarium, mit dem staatliche Grundrechtseingriffe auf ihre Verfassungsmäßigkeit hin geprüft werden, ist in Gestalt des Grundsatzes der Verhältnismäßigkeit längst viel feiner austariert. Hier spielt die Abwägung zwar ebenfalls eine wichtige Rolle, hat ihren Ort aber erst auf der letzten Stufe. Die Abwägung ist eingebunden in den wichtigsten verfassungsrechtlichen Prüfungsmaßstab, den unsere Rechtsordnung kennt: das Verhältnismäßigkeitsprin $\operatorname{zip}^{70}$.

68 Richtig Lepsius: Grundrechtsschutz (Fn. 33), S. 263: „Eine abstrakte Hierarchisierung der Grundrechte lässt das Grundgesetz aber nicht zu. Alle Grundrechte sind in der Verfassung normativ gleichberechtigt."

69 So treffend Josef Isensee: Virokratie, in: FAZ Nr. 128 v. 4. Juni 2020, S. 7. Er fügt hinzu: „Das gilt auch für das bislang als heilige Grundrechtskuh geschonte [...] Datenschutzgrundrecht."

70 Zum folgenden näher Horst Dreier: Vorbemerkungen vor Artikel 1 GG, In: ders. (Hrsg.), Grundgesetz-Kommentar, Bd. I, 3. Aufl., Rn. 145 ff. Tübingen (2013); Schulze-Fielitz (Fn. 16), Art. 20 (Rechtsstaat), Rn. 179 ff. 


\subsection{Verhältnismäßigkeitsprinzip}

Beim Verhältnismäßigkeitsprinzip handelt es sich um eine Art rationalitätsverbürgendes Prüfprogramm für die Verfassungsmäßigkeit staatlicher Grundrechtseingriffe. In einer mittlerweile kanonisierten und klar festgelegten Reihenfolge werden diese Eingriffe bestimmten Anforderungen unterworfen. Sie müssen geeignet, erforderlich und angemessen sein. Voranzustellen ist die Prüfung der Verfolgung eines legitimen Zwecks, weil sich nur unter Bezugnahme auf einen derartigen konkreten Zweck die Einhaltung der Kriterien überprüfen lässt. Ohne dessen Fixierung fehlte es an einer klaren Maßstäblichkeit. Wird eine der genannten Punkte nicht erfüllt, liegt also schon kein legitimer Zweck vor, oder ist die Maßnahme ungeeignet zu dessen Verfolgung, nicht erforderlich oder unangemessen, so liegt eine Grundrechtsverletzung vor. Halten die Maßnahmen der Prüfung hingegen auf allen vier Stufen stand, so haben wir es mit einem zulässigen Grundrechtseingriff zu tun ${ }^{71}$.

Für die folgende stichprobenartige Bestandsaufnahme ist zu beachten, dass bislang fast alle gerichtlichen Entscheidungen zur Corona-Pandemie im Wege des Eilrechtsschutzes ergangen sind. Hier nehmen die Gerichte nur eine summarische Prüfung vor. Die endgültige Klärung zentraler Streitpunkte bleibt der späteren genauen Prüfung im Hauptsacheverfahren vorbehalten. Das ist der eine Grund, warum selbst dann, wenn Gerichte Zweifel an der Gesetz- oder Verfassungsmäßigkeit bestimmter Maßnahmen hegten, die Entscheidung zuungunsten der betroffenen Antragsteller ausging. Ein zweiter, damit eng zusammenhängender Punkt: Wegen der unsicheren Sach- und Faktenlage, der in ständiger Bewegung befindlichen virologischen und epidemiologischen Erkenntnisse und der schwierigen prognostischen Lage kommt der Exekutive ein weiter Ermessens- und Gestaltungsspielraum („Einschätzungsprärogative“) $\mathrm{zu}^{72}$.

Legitimer Zweck. Es dürfte kein vernünftiger Zweifel daran bestehen, dass die zur Bekämpfung von COVID 19 ergriffenen Maßnahmen, die dem Schutz der Bevölkerung vor der Ausbreitung des Virus dienen sollen, einen legitimen Zweck verfolgen. Fraglich könnte höchstens sein, ob der eigentliche Zweck nicht letztlich der Schutz des Gesundheitssystems und insbesondere der Intensivstationen vor Überlastung ist ${ }^{73}$ - sei es, weil man die Verbreitung des Virus auf Dauer ohnehin nicht verhindern kann („Herdenimmunität“ oder „lernen, mit dem Virus zu leben“), sei es, weil das Virus zwar hochinfektiös, aber keineswegs hochpathogen ist, es viele symptomfreie Verläufe gibt und für Personen unter 45 Jahren im statistischen Durchschnitt weniger gefährlich als eine Grippe ist.

71 Die Gerichte gehen oft schulmäßig bei der Prüfung vor. Siehe beispielhaft NdsOVG v. 27. April 2020 - 13 MN 98/20, abgedruckt in: NdsVB1. 2020, S. 243-249 (248 f.).

72 Siehe etwa BayVGH v. 30. März 2020, 20 NE 20.632, Rn. 60.

73 Darauf insistierend Oliver Lepsius: Vom Niedergang grundrechtlicher Denkkategorien in der Corona-Pandemie, Verfassungsblog vom 6. April 2020 (https://verfassungsblog.de/vomniedergang-grundrechtlicher-denkkategorien-in-der-corona-pandemie/). 
Geeignetheit. An der Geeignetheit dürfte kaum eine der getroffenen Maßnahmen scheitern ${ }^{74}$. Denn auch Eingriffe, die ersichtlich über das Ziel hinausschießen, können geeignet zur Zweckerreichung sein. So müsste man es als durchaus geeignet ansehen, sämtliche Einwohner der Bundesrepublik Deutschland in eine lange Quarantäne zu schicken. In diesem Sinn hat auch das Bundesverfassungsgericht davon gesprochen, es könne durchaus angenommen werden, ,dass die vollständige soziale Isolation der gesamten Bevölkerung den besten Schutz gegen eine Infektion bietet. “75 Nur von vornherein gänzlich ungeeignete Mittel scheitern auf dieser Stufe, auf der es wegen der Zweck-Mittel-Relation um empirisch-technische Fragen der Tauglichkeit eines bestimmten Mittels zur Erreichung des erstrebten Zwecks geht ${ }^{76}$. Auf politische oder sonstige Wertungsfragen kommt es hier noch nicht an, wohl aber auf Wissen und Expertise $^{77}$. Von daher sind hier vor allem die Erkenntnisse der Virologie, Epidemiologie und Medizin gefragt.

Erforderlichkeit. Mit dem Kriterium der Erforderlichkeit wird im Sinne eines Interventionsminimums geprüft, ob es möglicherweise mildere, also weniger intensiv in die Grundrechtssphäre eingreifende Mittel gibt, die aber mit annähernd gleicher Effektivität das angestrebte Ziel erreichen.

Hier sind die Fälle zu verorten, in denen es (wie häufig zu Beginn der Pandemie) pauschale, keinerlei Ausnahmen zulassende Verbote etwa von Versammlungen oder von Gottesdiensten gegeben hatte. Sie wurden von den Gerichten eben wegen dieser Pauschalität und der darin liegenden fehlenden Erforderlichkeit aufgehoben ${ }^{78}$.

Geradezu ein Musterfall stellt die Entscheidung des Bundesverfassungsgerichts zu einer niedersächsischen Corona-Verordnung vom April 2020 dar, in der auch Zusammenkünfte in Kirchen und anderen Gotteshäusern ausnahmslos verboten worden waren. Diese Verordnung wurde vom Bundesverfassungsgericht vorläufig insoweit außer Vollzug gesetzt, ,als danach ausgeschlossen ist, auf Antrag im

74 Ein Kandidat wären vielleicht die Beherbergungsverbote, die im Oktober 2020 von den Verwaltungsgerichten mehrerer Bundesländer aufgehoben worden waren. Vgl. Henrik Eibenstein: Persona non grata dank Inzidenzwert, in: COVuR (COVID-19 und alle Rechtsfragen zur Corona-Krise) 1, Heft 13, S. 688-692 (2020). Auch das kuriose Verbot, allein auf einer Parkbank sitzend ein Buch zu lesen, ließe sich hier verorten. OVG Münster, Beschluss v. 20. November 2020, Az.: 13 b 1770/20.NE, hat die Quarantänepflicht für Auslandsrückkehrer aus Gebieten mit gleichen oder niedrigeren Inzidenzwerten als ungeeignet bezeichnet und sie insofern (auch wegen eines Gleichheitsverstoßes) aufgehoben.

75 BVerfG, Beschluss v. 12. Mai 2020, 1 BvR 1027/20, Rn. 7 - was aber eben viel zu weit ginge.

76 Beispiel: Ungeeignet wäre die Verpflichtung zum Tragen einer Alltagsmaske, wenn deren absolute Wirkungslosigkeit medizinisch feststünde.

77 Deswegen hielt Max Weber die Beurteilung von Zweck-Mittel-Relationen einer rationalen Diskussion für zugänglich. Vgl. Horst Dreier: Max Webers Postulat der Wertfreiheit in der Wissenschaft und die Politik, In: Horst Dreier/Dietmar Willoweit (Hrsg.), Wissenschaft und Politik, S. 35-70 (58 ff.) Stuttgart (2010).

78 Speziell zu den Demonstrationsverboten ausführlich Berit Völzmann: Versammlungsfreiheit in Zeiten von Pandemien, in: DÖV S. 893-904 (2020). 
Einzelfall Ausnahmen von dem Verbot zuzulassen. "79 Die Antragsteller hatten geltend gemacht, Abstandsregeln und andere Hygienemaßnahmen vorzusehen, mit denen „eine relevante Erhöhung der Infektionsgefahr zuverlässig“ ausgeschlossen werden konnte $^{80}$. Auch die umstrittenen Beherbergungsverbote dürften hier einzuordnen sein, wenn sie nicht ohnehin als von vornherein ungeeignet angesehen wurden ${ }^{81}$; de facto monierten die Gerichte aber vor allem, dass es an einem sachlichen Grund für die Anordnung und insbesondere für die Ungleichbehandlung unterschiedlicher Personengruppen (Studierende und Pendler einerseits, Touristen mit Übernachtung in Hotels andererseits) gefehlt habe. Insofern kommt neben den Freiheitsrechten auch dem Recht auf Gleichheit gemäß Art. 3 Abs. 1 GG eine bedeutende Rolle zu. Mit ausführlicher Begründung verneinte das OVG Lüneburg die Erforderlichkeit bei der Anordnung einer Sperrzeit und eines Alkohol-Außer-Haus-Verkaufsverbotes in Gastronomiebetrieben ${ }^{82}$.

Wie bei der Geeignetheit, so sind auch hier zur Feststellung der Erforderlichkeit naturwissenschaftliche Erkenntnisse insbesondere virologischer und epidemiologischer Art gefragt. Weil aber namentlich bei der Beurteilung der gleichen Effektivität der Maßnahme Prognosen und Einschätzungen eine große Rolle spielen, nimmt der Anteil von politisch und gesellschaftlich wertenden Aspekten naturgemäß $\mathrm{zu}$.

Angemessenheit (auch: Zumutbarkeit, Proportionalität, Verhältnismäßigkeit im engeren Sinne). Erst auf der Stufe der Angemessenheit kommt es zu den oben angesprochenen Abwägungsprozessen. Hier geht es um eine adäquate Relation zwischen der Schwere der grundrechtlichen Beeinträchtigung und der Bedeutung des mit der Maßnahme verfolgten öffentlichen Belanges in einer konkreten Konfliktsituation $^{83}$. Der Grundrechtseingriff muss in Maß und Umfang ,noch in einem vernünftigen Verhältnis zu den der Allgemeinheit erwachsenden Vorteilen stehen“"84. In Bezug auf die Corona-Pandemie bedeutet das, eine gewichtende Abwägung zwischen dem Ziel der Bekämpfung der Ausbreitung des Virus einerseits und der mit den Maßnahmen verbundenen umfassenden und massiven Freiheitseinschränkungen auf der anderen Seite vorzunehmen. Für die Beurteilung dieser letztlich gesellschaftspolitischen Frage verfügt die Virologie, die Epidemiologie und die

79 BVerfG, Beschluss v. 20. April 2020, 1 BvQ 44/20, Tenor und Rn. 14 f.

80 BVerfG, Beschluss v. 20. April 2020, 1 BvQ 44/20, Rn. 14.

81 So formulierte etwa das OVG Lüneburg in seinem Beschluss v. 15. Oktober 2020, 13 MN 371/20, Rn. 54, es gebe ,bereits erhebliche Zweifel an der Eignung und Erforderlichkeit des Beherbergungsverbots zur Erreichung des legitimen Ziels der Verhinderung der weiteren Ausbreitung von COVID-19.“ Das wird Rn. 55 ff. detailliert ausgeführt. Auf jeden Fall fehle es aber an der Angemessenheit (ebd., Rn. 62 ff.).

82 OVG Lüneburg, Beschluss v. 29.10. 2020, 13 MN 3939/20, Rn. 55 ff.

83 Es geht nicht um eine allgemein hierarchisierende Abwägung der Rechtsgüter als solcher, „,sondern es wird punktuell über die Angemessenheit von Konkretisierungsszenarien entschieden“ (Lepsius: Grundrechtsschutz [Fn. 33], S. 262).

84 So BVerfGE 76, 1 (51). In unzähligen weiteren Entscheidungen davor und danach finden sich ähnliche Wendungen. 
allgemeine Medizin über keine wissenschaftliche Expertise und kein abrufbares Verfügungswissen. Vielmehr liegt auf der Hand, dass bei Bewertung und Gewichtung der Rechtsgüter, die auf dem Spiel stehen, subjektive Präferenzen sozialer, politischer, ökonomischer, kultureller und sonstiger Art besonders hoch zu veranschlagen sind. Hier geht es um Wertentscheidungen, für die kein rationales oder empirisches Verfahren zur Verfügung steht.

Vor diesem Hintergrund entfaltet der oben behandelte Parlamentsvorbehalt ${ }^{85}$, der solche Fragen dem politischen Zentralorgan überantwortet, seine grundrechtliche Pointe. Infolge der Offenheit des politischen Prozesses ist der Entscheidungsspielraum weitaus größer als bei der Fixierung der geeigneten und erforderlichen Maßnahmen. Auf der Ebene der Angemessenheit können sich die staatliche Organe zur Rechtfertigung der von ihnen zu treffenden Entscheidungen eben nicht auf „wissenschaftliche“ Erkenntnisse berufen - was in der öffentlichen Präsentation nicht immer hinlänglich klargesehen, zuweilen wohl auch bewusst anders dargestellt wird ${ }^{86}$.

Ungeachtet der staatlichen Einschätzungsprärogative haben auch hier die Gerichte nicht selten Schutzmaßnahmen gegen die Ausbreitung der Pandemie als unangemessen und damit als verfassungswidrig eingestuft. Ein sehr früher Fall war die Aufhebung des für Ostern 2020 angeordneten Verbotes tagestouristischer Ausflüge an die Ostseeküste und andere Orte des Landes auch für Einheimische durch das dortige $\mathrm{OVG}^{87}$. Desgleichen hat etwa der Verwaltungsgerichtshof BadenWürttemberg die Beherbergungsverbote vom Oktober 2020 eingeordnet, weil er diese zwar auf einen legitimen Zweck gerichtet und (im Unterschied zu anderen Gerichten) auch als geeignet und erforderlich ansah, sie aber für unverhältnismäßig im engeren Sinne erachtete: „Eingriffszweck und Eingriffsintensität stehen nicht in einem angemessenen Verhältnis zueinander. "88Auch die sehr strengen

85 Siehe oben unter Punkt 2.1.

86 Klar und pointiert hingegen Lepsius: Grundrechtsschutz (Fn. 33), S. 271: „Wenn sich die politische Entscheidungsfindung von der Risikoeinschätzung etwa des Robert-Koch-Instituts oder der örtlichen ,Haus-Virologen“ abhängig macht, wird es noch unwahrscheinlicher werden, dass konfligierende Grundrechte überhaupt erkannt, geschweige denn ausgeglichen werden. Das ist kein Vorwurf an die Experten. Ihre Aufgabe liegt nicht im Blick auf das gesellschaftliche Ganze mit all seinen Konflikten, sondern auf das Spezielle und Partikulare, für das allein sie Expertise behaupten können. Man darf von Experten keine Relationierung von Grundrechten erwarten, weil das ihre Expertise überfordern würde. Die Risikoeinschätzung des RKI ist als Leitkriterium für eine Abwägung grundrechtlicher Schutzgüter schon deswegen ungeeignet, weil das RKI von seinem Aufgabenzuschnitt her ausschließlich dem Gesundheitsschutz dient. [...] Das RKI ist nicht dafür zuständig, andere Grundrechte damit abzugleichen. Es kann, soll und will Grundrechtskonflikte nicht behandeln. " Der Virologe Christian Drosten hat diesen Primat der Politik wiederholt betont.

87 OVG Greifswald, Beschluss v. 9. April 2020 - 2 km 281/20 OVG.

88 VGH Baden-Württemberg, Beschluss v. 15. Oktober 2020, 1 S. 3156/20, Rn. 20 ff. (Zitat: Rn. 32). 
Ausgangsbeschränkungen im Saarland vom April 2020 wurden vom dortigen Verfassungsgerichtshof als zum Teil ,unzumutbar" und ,unangemessen“ 89 bezeichnet.

Das Problem der nicht-intentionalen Nebenfolgen. Es ist schon, wie die - ihrerseits keineswegs einheitliche - Judikatur zeigt, nicht ganz einfach, die direkten Folgen staatlicher Eingriffe auf der Grundrechtsseite der Betroffenen in ein angemessenes Verhältnis zu den mit dem Eingriff verfolgten staatlichen Belangen zu setzen. Es kommt aber noch eine Problemdimension hinzu, die man als nicht-intentionale Nebenfolgen umschreiben kann ${ }^{90}$. Das bedeutet: Man darf nicht allein auf das eigentliche Ziel (etwa: Senkung der Infektionsrate) und diejenigen Grundrechtseingriffe, die zur Verfolgung dieses Ziels dienen sollen (etwa: Einschränkung der Bewegungsfreiheit), schauen, sondern muss das Spektrum erweitern und auch die weiter entfernten Nebenfolgen dieser Maßnahmen beachten, die sich eher indirekt und mittelbar aus ihnen ergeben ${ }^{91}$. Konkret gesprochen: Die in Ausrichtung auf das vorrangige Ziel der Eindämmung der Pandemie ergriffenen drastischen Maßnahmen bringen nicht nur für alle direkt Betroffenen schwere Freiheitseinschränkungen mit sich. Die Maßnahmen ziehen ihrerseits Folgen nach sich, die zwar gewiss nicht beabsichtigt sind, aber mit den staatlichen Regelungen in einem gewissen Kausalitätszusammenhang stehen. Als Stichworte seien genannt: der Anstieg häuslicher Gewalt aufgrund der Kontaktverbote und Ausgangsbeschränkungen; Verringerung von Bildungschancen durch Schulschließungen; schwere Krankheitsverläufe bei älteren Menschen aufgrund ihrer Isolation in Heimen und Krankenhäusern; Fehlkonzentration medizinischer Kapazitäten aufgrund der Fixierung auf COVID-Patienten. Die Liste ließe sich verlängern.

Es geht hier nicht darum, irgendwelche „Gegenrechnungen“ aufzumachen, sondern sich vom virologischen Tunnelblick auf reine Infektionszahlen zu lösen und stattdessen zu einer Gesamtbetrachtung zu gelangen. Dazu gehört die Anerkennung der Tatsache, dass die staatlich verordneten Maßnahmen, die mit Blick auf die Pandemie den Schutz von Leben und Gesundheit bezwecken, an anderer Stelle gerade Einbußen dieser (und anderer) Rechtsgüter nach sich ziehen. Diese Aspekte dürfen bei der Güterabwägung nicht ausgeblendet und dem Primat eines seuchenpolizeilichen Imperativs geopfert, sondern müssen in eine Art Gesamttableau mit eingestellt werden. Erst die Einbeziehung der zu erwartenden nicht-intendierten Nebenfolgen und der sonstigen mittelbaren Auswirkungen macht die ganze Komplexität der Abwägung kollidierender Güter deutlich. Die schwierige und voraussetzungsvolle Aufgabe der Gewichtung der einzelnen Belange fällt zuvörderst in die Kompetenz der zuständigen staatlichen Organe. Ihnen kommt bei dieser überaus komplexen Aufgabe ein weiter Ermessens- und Gestaltungsspielraum zu. Gerade deswegen besteht die Verpflichtung zu einer umfassenden Bewertung und Gewichtung aller betroffenen

89 Saarländischer Verfassungsgerichtshof, Beschluss v. 28. April 2020, Lv 7/20, Umdruck S. $16,17$.

90 Es ist dies ein allgemeines Phänomen, das besonders klar von Max Weber analysiert wurde; vgl. nochmals Dreier: Postulat (Fn. 77), S. 60 f.

91 Daran hat es insbesondere zu Beginn der Pandemie oft gefehlt; kritisch dazu etwa Hinnerk Wißmann: Alle Macht dem Virus?, in: FAZ Nr. 68 v. 20. März 2020, S. 9. 
Belange in einer Gesamtbetrachtung. Eine starre Fixierung auf Infektionsstatistiken mit ohnehin oft uneindeutigem Aussagegehalt genügt nicht. Wenn schon die Entscheidungsgrundlagen nicht hinlänglich breit erfasst werden, werden entsprechende Defizite auf die Entscheidung selbst durchschlagen. Das zeigt zugleich: Der Entscheidungsspielraum ist zwar weit, aber nicht grenzenlos. Auch insofern werden die Gerichte das letzte Wort haben.

Open Access Dieses Kapitel wird unter der Creative Commons Namensnennung - Nicht kommerziell - Keine Bearbeitung 4.0 International Lizenz (http://creativecommons.org/ licenses/by-nc-nd/4.0/deed.de) veröffentlicht, welche die nicht-kommerzielle Nutzung, Vervielfältigung, Verbreitung und Wiedergabe in jeglichem Medium und Format erlaubt, sofern Sie den/die ursprünglichen Autor(en) und die Quelle ordnungsgemäß nennen, einen Link zur Creative Commons Lizenz beifügen und angeben, ob Änderungen vorgenommen wurden. Die Lizenz gibt Ihnen nicht das Recht, bearbeitete oder sonst wie umgestaltete Fassungen dieses Werkes zu verbreiten oder öffentlich wiederzugeben.

Die in diesem Kapitel enthaltenen Bilder und sonstiges Drittmaterial unterliegen ebenfalls der genannten Creative Commons Lizenz, sofern sich aus der Abbildungslegende nichts anderes ergibt. Sofern das betreffende Material nicht unter der genannten Creative Commons Lizenz steht und die betreffende Handlung nicht nach gesetzlichen Vorschriften erlaubt ist, ist auch für die oben aufgeführten nicht-kommerziellen Weiterverwendungen des Materials die Einwilligung des jeweiligen Rechteinhabers einzuholen. 